\title{
ALBEDO OF SNOW, ICE SHEETS AND SNOW-COVERED SEA ICE IN GENERAL CIRCULATION MODELS \\ (Abstract)
}

\author{
by
}

Susan E. Marshall

(Geography Department, University of Colorado, Boulder, CO 80309, U.S.A.)

Stephen G. Warren

(Glaciology Section, Antarctic Division, Earth Sciences School, University of Melbourne, Parkville, Victoria 3052, Australia)

We have developed a physically-based parameterization for snow albedo, for the visible and near-infrared spectral regions used in general circulation models (GCMs). Snow albedo depends primarily on snow grain size, and also on solar zenith angle, snow thickness, impurity content, and atmospheric transmittance. This parameterization is now available as a Fortran subroutine. Simpler, but less accurate, parameterizations have also been developed which depend only on grain size or thickness. Since GCMs do not compute snow grain size, we also developed a method to estimate grain size based on the air temperature and the snow age.

Our parameterization for snow albedo is being incorporated in the NCAR Community Climate Model $(C C M)$ in place of the existing empirical parameterization

\begin{abstract}
for snow albedo, to determine the effect of this improvement on the model's performance, and the results will be discussed. However, additional aspects of the treatment of the radiative properties of snow and ice were also capable of improvement and are being changed in the CCM. In particular, it is important to recognize that sea ice is often snow-covered and in that case has an albedo as high as that of snow, and that southern hemisphere sea ice is nearly always snow-covered, even through the melting season. The surface albedo for the Antarctic ice sheet should be about 0.83 , but it had been set to 0.71 in the CCM. The CCM has been calculating temperatures too warm over Antarctica, and this low albedo contributed to that error.
\end{abstract}

\section{HYDRODYNAMIC MODEL OF GLACIERS AND ICE SHEETS INTERACTED WITH OCEAN}

\section{(Abstract)}

by

V.L. Mazo

(Institute of Geography, Academy of Sciences, Staromonetny 29, 109017 Moscow, U.S.S.R.)

Tidewater glaciers and large ice sheets, e.g. the Antarctic ice sheet and a late-Würm Arctic ice sheet, are complex but single dynamic systems composed of terrestrial, marine and floating parts. Morphology and dynamics of the different parts are different. The terrestrial parts are convex and their dynamics are controlled by shear stress only (the longitudinal stress is zero); the floating parts are concave and their dynamics are controlled by longitudinal stress only (the shear stress is zero). To connect the different parts we should consider transitional zones where shear and longitudinal stresses are comparable.

To describe glacier and ice-sheet dynamics, longwave approximation of the first order is used. In this approximation it is impossible to connect terrestrial and floating parts dynamically, only morphologically and kinematically. It means that the first-order longwave approximation is not sufficient.

If the transitional zone between the terrestrial and floating parts is long in comparison to ice thickness (in hydrodynamics the term "weak" is used) we can do the next step in the longwave approximation to describe the single dynamical system consisting of the terrestrial and floating parts and the weak transitional zones (ice streams). It is a purely hydrodynamical approach to the problem without ad hoc hypothesis.

The presented model is a non-stationary three-dimensional hydrodynamic model of glaciers and ice sheets interacted with ocean, involving the conditions of ice continuity and dynamic equilibrium, ice rheology, and boundary conditions on the free surface (dynamic and kinematic) and on the bed (ice freezing or sliding). Longwave approximation is used to reduce the threedimensional model to a two-dimensional one. The latter consists of (1) evolution equations for grounded and floating parts and weak transitional zones; (2) boundary conditions on the fronts (e.g. the conditions of calving); (3) equations governing the junctions of the parts (the most important junction is the grounded line) with the conditions connecting the evolution equations. 